\title{
An Exploratory Study of Radiation Dermatitis in Breast Cancer Patients
}

\author{
ELEFTHERIA ALEXOPOULOU ${ }^{1}$, THEODORA KATSILA ${ }^{1,2}$, MARIA TOLIA $^{3}$, NIKOLAOS TSOUKALAS ${ }^{4}$, \\ MICHAEL LEONTSINIDIS ${ }^{5}$, GEORGE KYRGIAS ${ }^{6}$, VASILIOS KOULOULIAS ${ }^{7}$, \\ GEORGE P. PATRINOS $^{2}$, DESPOINA SPYROPOULOU ${ }^{1}$ and DIMITRIOS KARDAMAKIS ${ }^{1}$ \\ ${ }^{1}$ Department of Radiation Oncology, University of Patras Medical School, Patras, Greece; \\ ${ }^{2}$ Department of Pharmacy, University of Patras, Patras, Greece; \\ ${ }^{3}$ Department of Radiotherapy, Faculty of Medicine, School of Health \\ Sciences, University of Thessaly, Larisa, Greece; \\ ${ }^{4}$ Department of Oncology, Veterans Hospital (NIMTS), Athens, Greece; \\ ${ }^{5}$ Department of Public Health, University of Patras Medical School, Patras, Greece; \\ ${ }^{6}$ Department of Radiotherapy, Larisa University Hospital, Larisa, Greece; \\ ${ }^{7}$ Radiotherapy Unit, ATTIKON University Hospital, University of Athens Medical School, Athens, Greece
}

\begin{abstract}
Background/Aim: Radiation dermatitis is observed in $95 \%$ of breast cancer patients receiving radiotherapy. The aim of this study was to explore the correlation between protein expression in tumor cells and the risk of developing radiation dermatitis. Patients and Methods: Breast cancer patients receiving postoperative radiotherapy were included in this study. Tumor specimens from 122 patients were examined by immunohistochemistry for the expression of Ki67, ataxia telangiectasia mutated (ATM) kinase, hypoxia-inducible factor-1-alpha (HIF-1a), inducible nitric oxide synthase (iNOS), and a-glucosidase $(a G l u c)$. The findings were correlated with the occurrence and severity of radiation dermatitis (Radiation therapy oncology group-RTOG grading scale), taking into consideration body weight and skin type (Fitzpatrick system). Data were explored further via pathway and network analyses. Results: Correlation of radiation dermatitis (RTOG scale) with the observed increased expression of Ki67, ATM, iNOS, HIF-la and aGluc, failed to reach statistical significance when skin type andlor body weight were considered. Network interactions of proteins involved in tumor growth (Ki67, ATM) and/or affect the oxidation state of the cell (HIF-1a, iNOS, aGluc) were revealed, that may
\end{abstract}

Correspondence to: Dimitrios Kardamakis, Department of Radiation Oncology, University of Patras Medical School, University Campus, 26504 Patras, Greece. Tel: +30 2610999540, Fax: +30 2613604007, e-mail: kardim@upatras.gr

Key Words: Breast cancer, radiotherapy, radiodermatitis. contribute to the risk of developing acute radiation dermatitis. Conclusion: Correlation of the increased expression of the studied proteins and the occurrence and severity of radiation dermatitis in women undergoing postoperative radiotherapy, failed to reach statistical significance. Pathway and network analyses predicted that vasodilation and angiogenesis may contribute to radiationinduced dermatitis via mechanisms that need to be further explored. Our strategy serves as a paradigm for coupling histopathological data to molecular findings and network analyses for risk assessment in the clinic.

Since the first application of X-ray irradiation in cancer therapy (1), radiotherapy has been extensively used in breast cancer treatment in an adjuvant setting after lumpectomy or after mastectomy, aiming to reduce the risk of loco-regional recurrence (2).

In this setting, the most common side-effect of radiotherapy is the acute radiation-induced injury of the skin, known as radiation dermatitis. According to the Radiation Therapy Oncology Group (RTOG) toxicity criteria, it is ranging from redness - erythema to dry or wet desquamation and on rare occasions, it may progress to deep ulceration (3). The degree of skin reaction depends on several factors, such as: irradiation in places where there is contact between surfaces, areas with folds or where skin integrity has been ruptured, concurrent chemotherapy or immunotherapy, associated medical conditions or co-morbidity, chronic exposure to the sun, smoking, localization of the tumor or field treated, tumor staging, large irradiated volume, high dose of total radiation, fractionation of irradiation, the type 
of energy used and patient-related (skin type, body weight and intrinsic radiosensitivity) factors $(4,5)$. As erythema is usually experienced at irradiation doses greater than $20 \mathrm{~Gy}$ (6), skin health is one of the main aspects that radiation oncologists take upon serious consideration for breast cancer patients, since the prescribed doses reach 50-60 Gy.

Exposing the skin to ionizing irradiation leads to a complex pattern of direct injury and inflammatory cell recruitment, involving damage to epidermal basal cells, endothelial cells, and vascular components. Therefore, skin reaction to radiation is a complex, multifactorial clinical entity that results from the interaction of multiple genes in different cellular pathways, including genes related to DNA damage and repair, apoptosis, profibrotic and inflammatory cytokines and endogenous antioxidant enzymes (7). A challenge in modern research is to identify the multiple genetic variants which affect the cellular and clinical phenotype and may therefore be useful as biomarkers to predict normal tissue response after radiation therapy (8). Single nucleotide polymorphisms in genes related to DNA repair mechanisms and oxidative stress have been reported to modify the risk of acute normal tissue complications in breast cancer patients (9). Many efforts have been made to reveal the mechanism underlying this side effect that limits radiation therapy efficacy and applicability (10-17).

The present clinico-pathological study aimed to correlate the appearance and severity of radiation dermatitis with the expression of ataxia telangiectasia mutated (ATM) kinase, nitric oxide synthase (iNOS, the inducible isoform), hypoxiainducible factor-1-alpha (HIF-1 $\alpha$ ), a-glucosidase (aGluc) and the cellular proliferation marker Ki67, in tumor cells from breast cancer patients undergoing postoperative radiotherapy. Furthermore, the interactions between proteins were studied using pathway and network analyses. Such DNA-damage and/or cell-cycle markers have been reported to be released by tumor cells exposed to ionizing radiation mediating cell signaling or inflammation (18). Upon lethal stimulation (apoptotic or necrotic signals), irradiated cancer cells release immunostimulatory molecules leading to "immunogenic cell death" $(19,20)$. Even though strictly intracellular, such markers are present in the extracellular space via nonclassical secretion pathways (21).

\section{Patients and Methods}

Recruitment of patients. The study was conducted at the Department of Radiation Oncology and Stereotactic Radiotherapy, University Hospital of Patras, Greece, from June 2010 to May 2011. The study protocol was approved by the local ethical committees according to national requirements. Patient recruitment and sample collection were performed with informed consent. One hundred and twentytwo female patients with histologically proven breast cancer entered the study and all, but one, were treated with postoperative radiotherapy according to the current National Comprehensive
Cancer Network (NCCN) guidelines (13). The classification of patients' skin type was performed by two observers (EA and DS), based on the Fitzpatrick scale (22). Demographic and clinical characteristics of the patients are shown in Table I.

Radiotherapy. Radiotherapy was delivered postoperatively to the chest wall in 38 patients $(31.2 \%)$ or to the breast in 84 patients $(68.8 \%)$. One hundred five patients $(86.1 \%)$ were treated with $3 \mathrm{D}$ conformal radiotherapy (3D-CRT) with a daily dose of 1.8-2.0 Gy to a median total dose of $50 \mathrm{~Gy}$ (range 50-58 Gy). Seventeen patients $(13.9 \%)$ were treated with a hypofractionated scheme receiving a total dose of 40.5 Gy in 15 fractions.

Patient evaluation. The skin reaction to radiation was evaluated according to the RTOG acute radiation toxicity scoring system. Evaluation was applied in different phases: at the radiotherapy and periodically 2, 4, 6 months after radiation treatment was completed (3). A moisturizing cream or the appropriate ointment, based on the Departments policy, was prescribed to the patients only after skin lesions appeared, as a daily supportive care.

Immunocytochemistry. Breast tumor specimens were collected from patients who underwent surgery and stored at $-20^{\circ} \mathrm{C}$ prior to analysis. Immunohistochemistry was performed on $4-\mu \mathrm{m}$-thick, formalin fixed, paraffin embedded slides mounted on gelatin-coated glass slides. Deparaffinization, rehydration and antigen retrieval were performed in an electric pressure cooker using trilogy retrieval solution (Cell Marque, Hot Springs, AR, USA) for $30 \mathrm{~min}$. The sections were incubated for $1-2 \mathrm{~h}$ at room temperature with primary polyclonal antibodies against iNOS (dilution 1:1000, EMD Millipore, Temecula, CA, USA) and aGluc (dilution 1:500, SantaCruz, Dallas Tx, USA), and monoclonal antibodies against HIF-1 $\alpha$ (dilution 1:500, Neomarkers, Bioanalytica, Fremont, USA), Ki67 (dilution 1:50, Dako, Carpinteria, CA, USA) and ATM (dilution 1:500, Novus Biologicals, Littleton, CO, USA). Sections were then incubated with Dako Envision Labelled Polymer (Dako, Carpinteria, CA, USA) for $30 \mathrm{~min}$. Diaminobenzidine (Dako, Carpinteria, CA, USA) was used as chromogen. Nuclear stain was considered as positive staining. Primary antibodies were replaced with Tris buffer solution $1 \%$ for negative control slides. As previously described (23), the evaluation of tissue sections was performed by two independent observers (EA and DS), blinded to the clinical characteristics of the tumors and the clinic-pathological data of the patients. To address immunoreactivity, the $\mathrm{H}$-score was calculated using the following mathematical formula: $\mathrm{H}$-score $=(1 \times$ percentage of weakly positive cells $)+(2 \times$ percentage of moderately strong positive cells $)+$ ( $3 \times$ percentage of strongly positive cells), ranging from 0 to 300 . The intensity and the $\%$ percentage of positively stained cells as well as the localization of the staining reaction (nuclear, cytoplasmic, or both nuclear and cytoplasmic) was recorded.

Pathway and Network analysis. For pathway analysis, HIF-1 $\alpha$, Ki67, ATM and iNOS protein-protein interactions, both direct (physical) and indirect (functional), were investigated using Search Tool for the Retrieval of Interacting Genes/Proteins (STRING) database (http://string-db.org/) $(24,25)$. Interactions were also searched and mined from InnateDB database (26). Expression networks were illustrated using Cytoscape 3.6.0 software (27).

Statistical analysis. Data analysis was performed using SPSS version 22.0 (SPSS Inc., Chicago, IL, USA). The results were 
Table I. Clinico-demographic characteristics of breast cancer patients.

\begin{tabular}{lcc}
\hline Clinical and demographic features & & \\
\hline Age in years [median (min-max)] & & {$[61(26-90)]$} \\
Patient weight [median (min-max)] & & {$[73(50-116)]$} \\
Skin type (Fitzpatrick scale) & & $(1.6 \%)$ \\
I & 2 & $(36.9 \%)$ \\
II & 45 & $(55.7 \%)$ \\
III & 68 & $(5.7 \%)$ \\
IV & 7 & \\
Tumor localization & & $(45.9 \%)$ \\
Right breast & 56 & $(53.3 \%)$ \\
Left breast & 65 & $(0.8 \%)$ \\
Both breasts & 1 & \\
Histology & & $(67.2 \%)$ \\
Ductal invasive & 82 & $(24.6 \%)$ \\
Ductal invasive + DCIS & 30 & $(5.7 \%)$ \\
Lobular invasive & 7 & $(2.5 \%)$ \\
Other & 3 & \\
T stage & & $(35.3 \%)$ \\
1 & 43 & $(45.9 \%)$ \\
2 & 56 & $(13.9 \%)$ \\
3 & 17 & $(4.9 \%)$ \\
4 & 6 & $(68.9 \%)$ \\
Type of surgery & & $(31.1 \%)$ \\
Breast conserving surgery & 84 & $(13.9 \%)$ \\
Mastectomy & 38 & \\
Radiotherapy schedule & & \\
3D-CRT & 104 & \\
Hypofractionated & 17 & \\
\hline
\end{tabular}

DCIS, Ductal carcinoma in situ; 3D-CRT, 3-dimensional conformal radiotherapy.

tabulated and analyzed using appropriate statistical techniques. To describe about the data, descriptive statistics, mean, and standard error were used. A $p$-value $<0.05$ was considered statistically significant for all tests. Zero-order and first-order partial correlation was used to investigate the association between the expression of the studied molecules (Ki67, ATM, HIF-1 $\alpha$, iNOS, aGluc) in tumor cells and the degree of radiation dermatitis (RTOG grading scale) in breast cancer patients, taking into account body weight and skin type. In addition, the Bootstrap method reinforced the exploratory process of partial association. Calculation of the minimum sample size using the G-Power 3 software showed that given a $\mathrm{QH} 0=0$, $\mathrm{\varrho H} 1=0.5, \alpha=0.05$, and $\mathrm{N}=122$, the statistical power was $99.9 \%$.

\section{Results}

Clinico-pathological observations. A total of 122 breast cancer patients, aged $60.8 \pm 2.5$ and weighing $73.7 \pm 12.3$, were enrolled in the study. Thirty-one patients $(25.4 \%)$ had no signs of acute skin toxicity, while 91 (74.6\%) developed radiation dermatitis. Table II displays the classification of patients according to skin type and the corresponding grade of skin toxicity. At the end of radiation treatment, 48 patients (39.4\%) experienced grade I skin toxicity, while 31 patients (25.4\%) developed grade II and 12 patients (9.8\%)
Table II. Distribution of skin toxicity grading for various skin types.

\begin{tabular}{ccccccc}
\hline & \multicolumn{5}{c}{ RTOG grading } \\
\cline { 2 - 7 } & & - & I & II & III & IV \\
\hline \multirow{2}{*}{ Skin type } & - & 0 & 0 & 0 & 0 & 0 \\
& I & 0 & 1 & 1 & 0 & 0 \\
& II & 11 & 17 & 10 & 7 & 0 \\
& III & 18 & 26 & 20 & 3 & 0 \\
& IV & 2 & 4 & 0 & 2 & 0 \\
& 31 & 48 & 31 & 12 & 0 \\
\hline
\end{tabular}

RTOG, Radiation Therapy Oncology Group.

experienced grade III radiation dermatitis. None of the participants showed grade IV skin toxicity. In total, $74.6 \%$ of the patients experienced any degree of skin toxicity. The immunohistochemical analysis of all tissue specimens was performed as previously described (23) and showed that the $\mathrm{H}$-score for ATM was 28.19 (range 0-60), for Ki67 was 31.39 (range 5-90), for iNOS was 28.85 (range 0-45), for HIF-1 $\alpha$ was 30.81 (range 0-70) and for aGluc was 26.88 (0-60).

Partial correlation analysis. No statistically significant correlations were obtained when radiation dermatitis (RTOG grading) and the increased expression of Ki67 (rho $=-0.112$, $p=0.218$, Bootstrap-bias $=0.001$ ), ATM ( $r h o=0.031, p=0.733$, Bootstrap-bias $=-0.002$ ), iNOS (rho $=0.057, p=0.531$, Bootstrapbias $=0.000)$, HIF- $1 \alpha(\mathrm{rho}=-0.105, p=0.249$, Bootstrap-bias $=-$ 0.002 ), and aGluc (rho $=-0.035, p=0.706$, Bootstrap-bias $=0.001$ ) were considered (Table III). When radiation dermatitis (RTOG grading), body weight, and the increased expression of Ki67 $($ rho $=-0.139, \quad p=0.129, \quad$ Bootstrap-bias $=0.008), \quad$ ATM $(\mathrm{rho}=0.022, \quad p=0.815, \quad$ Bootstrap-bias $=-0.005), \quad$ iNOS $(\mathrm{rho}=0.076, p=0.407$, Bootstrap-bias $=-0.001), \mathrm{HIF}-1 \alpha(\mathrm{rho}=-$ $0.143, p=0.118$, Bootstrap-bias $=0.004)$, and aGluc (rho $=-0.077$, $p=0.401$, Bootstrap-bias $=0.003$ ) were evaluated, data analysis resulted in no statistically significant correlations (Table IV). Radiation dermatitis (RTOG grading), skin type and the increased expression of Ki67 (rho $=-0.137, p=0.134$, Bootstrapbias $=0.002)$, ATM (rho $=0.018, p=0.844$, Bootstrap-bias $=-$ 0.001 ), iNOS (rho $=0.081, p=0.375$, Bootstrap-bias $=0.001$ ), HIF-1 $\alpha \quad($ rho $=-0.150, p=0.100$, Bootstrap-bias $=0.001)$, and aGluc (rho $=-0.078, p=0.397$, Bootstrap-bias $=0.003$ ) also failed to reach statistical significance (Table V).

Pathway and network analysis. The STRING database was interrogated for HIF-1 $\alpha$, Ki67 (MK167), ATM and iNOS (NOS2) and Homo sapiens (organism). Analysis was focused on i) "response to radiation" ( $p$-value of $1.409 \mathrm{e}-2$ for HIF-1 $\alpha$, ATM, IL1R1 and IL1B), ii). "regulation of inflammatory response" ( $p$-value of 3.629e-3 for IL6, IL1R1 
Table III. Partial correlation analysis revealed no statistically significant correlations between radiation dermatitis (RTOG grading) and the increased expression of the selected protein markers.

\begin{tabular}{|c|c|c|c|c|c|c|c|c|c|}
\hline & & & & & Ki67 & ATM & iNOS & HIF- $1 \alpha$ & aGluc \\
\hline \multirow[t]{7}{*}{ Spearman's rho } & RTOG & Correlation coefficient & & & -0.112 & 0.031 & 0.057 & -0.105 & -0.035 \\
\hline & & Significance (2-tailed) & & & 0.218 & 0.733 & 0.531 & 0.249 & 0.706 \\
\hline & & $\mathrm{N}$ & & & 122 & 122 & 122 & 122 & 122 \\
\hline & & Bootstrap & Bias & & 0.001 & -0.002 & 0.000 & -0.002 & 0.001 \\
\hline & & & Standard error & & 0.081 & 0.083 & 0.092 & 0.087 & 0.089 \\
\hline & & & $95 \%$ Confidence interval & Lower & -0.269 & -0.128 & -0.128 & -0.290 & -0.214 \\
\hline & & & & Upper & 0.040 & 0.189 & 0.229 & 0.061 & 0.142 \\
\hline
\end{tabular}

Bold values indicate two-tailed significance and the corresponding bootstrap biases; RTOG, Radiation Therapy Oncology Group; ATM, ataxia telangiectasia mutated kinase; iNOS, inducible nitric oxide synthase; HIF-1 $\alpha$, hypoxia-inducible factor-1-alpha; aGluc, a-glucosidase.

Table IV. Partial correlation analysis of radiation dermatitis (RTOG grading) and the increased expression of specific protein markers, adjusted for body weight.

\begin{tabular}{|c|c|c|c|c|c|c|c|c|c|}
\hline \multicolumn{5}{|c|}{ Control variables } & \multirow{2}{*}{$\begin{array}{c}\text { Ki67 } \\
-0.139\end{array}$} & \multirow{2}{*}{$\begin{array}{c}\text { ATM } \\
0.022\end{array}$} & \multirow{2}{*}{$\begin{array}{c}\text { iNOS } \\
0.076\end{array}$} & \multirow{2}{*}{$\begin{array}{c}\text { HIF- } 1 \alpha \\
-0.143\end{array}$} & \multirow{2}{*}{$\begin{array}{l}\text { aGluc } \\
-0.077\end{array}$} \\
\hline Weight & RTOG & Correlation coefficient & & & & & & & \\
\hline & & Significance (2-tailed) & & & 0.129 & 0.815 & 0.407 & 0.118 & 0.401 \\
\hline & & df & & & 119 & 119 & 119 & 119 & 119 \\
\hline & & Bootstrap & Bias & & 0.008 & 0.005 & -0.001 & 0.004 & 0.003 \\
\hline & & & Standard error & & 0.086 & 0.084 & 0.085 & 0.089 & 0.086 \\
\hline & & & $95 \%$ Confidence interval & Lower & -0.295 & -0.133 & -0.090 & -0.309 & -0.242 \\
\hline & & & & Upper & 0.038 & 0.195 & 0.245 & 0.030 & 0.094 \\
\hline
\end{tabular}

Bold values indicate two-tailed significance and the corresponding bootstrap biases; RTOG, Radiation Therapy Oncology Group; ATM, ataxia telangiectasia mutated kinase; iNOS, inducible nitric oxide synthase; HIF-1 $\alpha$, hypoxia-inducible factor-1-alpha; aGluc, a-glucosidase; df, degrees of freedom.

Table V. Partial correlation analysis of radiation dermatitis (RTOG grading) and the increased expression of specific protein markers, adjusted for skin type.

\begin{tabular}{|c|c|c|c|c|c|c|c|c|c|}
\hline \multicolumn{5}{|c|}{ Control variables } & \multirow{2}{*}{$\begin{array}{c}\text { Ki67 } \\
-0.137\end{array}$} & \multirow{2}{*}{$\begin{array}{c}\text { ATM } \\
0.018\end{array}$} & \multirow{2}{*}{$\begin{array}{c}\text { iNOS } \\
0.081\end{array}$} & \multirow{2}{*}{$\frac{\text { HIF- } 1 \alpha}{-0.150}$} & \multirow{2}{*}{$\begin{array}{c}\text { aGluc } \\
-0.078\end{array}$} \\
\hline Skin type & RTOG & Correlation coefficient & & & & & & & \\
\hline & & Significance (2-tailed) & & & 0.134 & 0.844 & 0.375 & 0.100 & 0.397 \\
\hline & & $\mathrm{df}$ & & & 119 & 119 & 119 & 119 & 119 \\
\hline & & Bootstrap & Bias & & 0.002 & -0.001 & 0.001 & 0.001 & 0.003 \\
\hline & & & Standard error & & 0.079 & 0.084 & 0.087 & 0.083 & 0.090 \\
\hline & & & $95 \%$ Confidence interval & Lower & -0.282 & -0.149 & -0.084 & -0.309 & -0.247 \\
\hline & & & & Upper & 0.017 & 0.190 & 0.263 & 0.013 & 0.110 \\
\hline
\end{tabular}

Bold values indicate two-tailed significance and the corresponding bootstrap biases; RTOG, Radiation Therapy Oncology Group; ATM, ataxia telangiectasia mutated kinase; iNOS, inducible nitric oxide synthase; HIF-1 $\alpha$, hypoxia-inducible factor-1-alpha; aGluc, a-glucosidase; df, degrees of freedom.

and IL1B), and iii) "response to wounding" ( $p$-value of $1.010 \mathrm{e}^{-4}$ for HIF-1 $\alpha$, NOS2, IL1B, IL6, VWF and PTGIR). The resulted predicted protein interactions are depicted in Figure 1 accompanied by their interaction (Figure 1A), evidence (Figure 1B) and confidence (Figure 1C) scores. Findings were in agreement with InnateDB outcomes. Networks were illustrated and explored further with Cytoscape. 


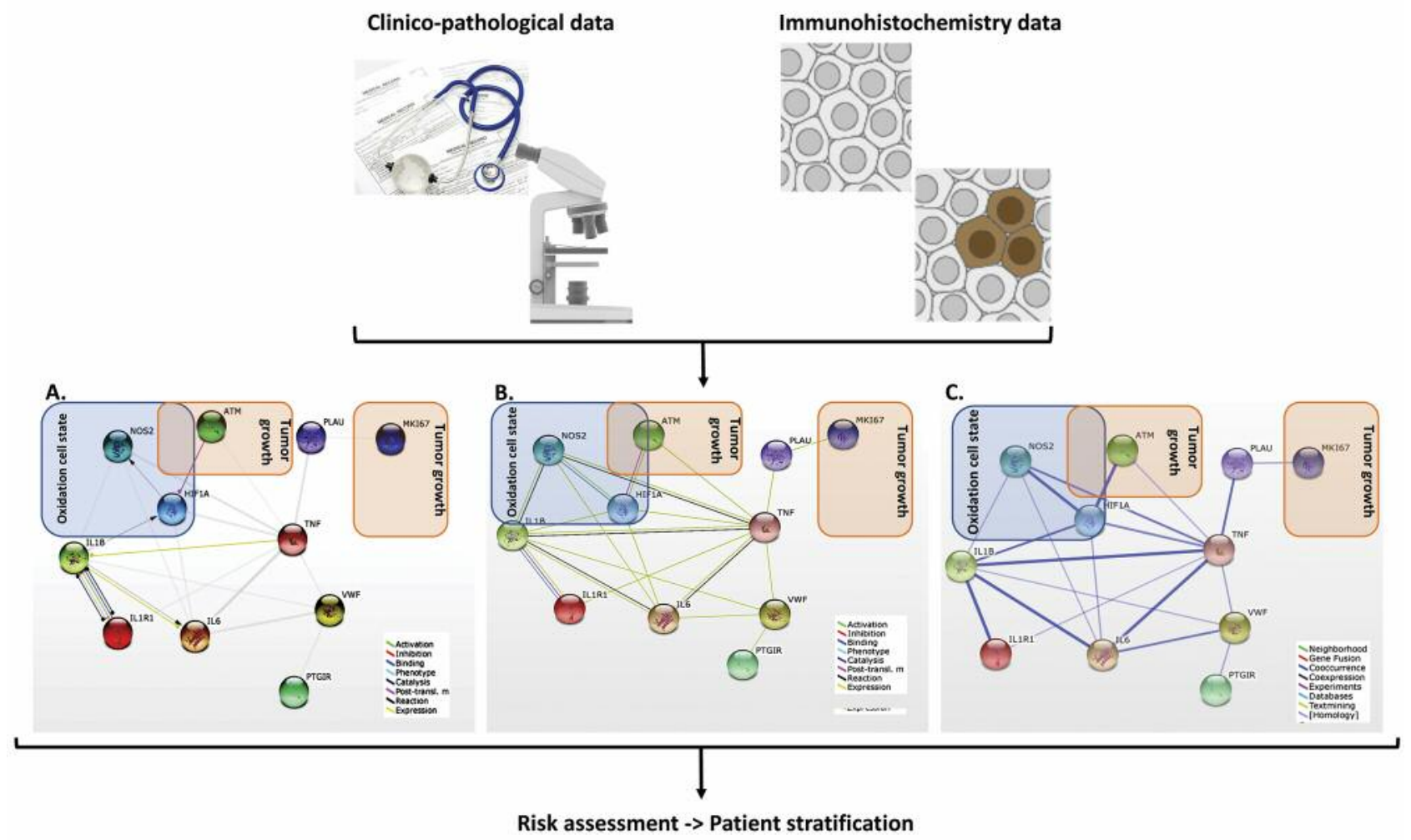

Figure 1. A schematic representation of clinico-pathological and immunohistochemical data coupled to network and pathways analysis applied to patient stratification and personalized radiotherapy. For each individual patient, several data sets were collected and upon their integration and analysis, information on specific module alterations were provided (such as tumor growth or oxidation cell state). Upon the STRING database interrogation for HIF-1a, Ki67 (MK167), ATM and iNOS (NOS2) and Homo sapiens (organism), the resulted predicted protein interactions are depicted accompanied by their interaction (A), evidence (B), and confidence $(C)$ scores. Such information may support evidence-based patient stratification.

\section{Discussion}

In the literature it is reported that approximately $90 \%$ of patients will develop skin erythema during a standard course of radiation therapy and $10 \%$ of them will manifest grade III radiation dermatitis (28), despite the progress of modern radiation techniques (29). Radiation therapy-induced acute dermatitis, though reversible in the vast majority of cases, can affect the radiotherapy schedule, negatively influence the quality of life of patients, and may require adequate treatment (30).

Factors that affect the occurrence and severity of radiation dermatitis caused by radiotherapy are the irradiated body surface area, the total dose and dose per fraction, the radiotherapy equipment used, the overall treatment time, as well as the concomitant chemotherapy, immunotherapy, and hormonal therapy (10). Another determining factor is the interval between chemotherapy and radiotherapy, where a period of 3 - 4 weeks is needed to ensure safety (31). It is well known that specific genes are associated with altered cellular radiosensitivity. For example, breast cancer patients that possess $A T M$ mutations were reported to exhibit an increase in subcutaneous late tissue effects after radiotherapy (32), although other studies have questioned any increased radiation-induced acute or late skin or subcutaneous reactions in this population (33). It has also been reported that collagen vascular diseases are not associated with increased radiation therapy complications (34).

In the current clinical study, we explored the expression of selected molecules with emphasis on DNA repair, tumor growth (Ki67, ATM) and/or affect the oxidation state of the cell (HIF-1a, iNOS, aGluc) on tumor cells and their association with the development of radiation dermatitis. The heterodimeric protein HIF- $1 \alpha$ is the major regulator of oxygen homeostasis $(35,36)$. In breast cancer, particularly, HIF- $1 \alpha$ overexpression has been demonstrated in ductal, in situ and invasive carcinomas (37) and hence, HIF-1 $\alpha$ polymorphisms have been examined as a marker of response to treatment (38). In our study, the correlation of HIF-1 $\alpha$ expression levels with radiation dermatitis failed to reach 
statistical significance. ATM kinase is involved in cellular stress responses, cell cycle check point control, and DNA repair. The clinical association between patients producing non-functional ATM and the subsequent responses to ionizing radiotherapy has been described, although ATM is not the only one responsible for adverse radiotherapy responses $(39,40)$. Our study did not show any association of ATM actinic dermatitis with ATM expression levels.

Focusing on Ki67 expression, no association with the occurrence of actinic dermatitis was reported. The Ki67 antigen is a nuclear protein associated with cellular proliferation, it is frequently used as a cell proliferation marker, and is often correlated with the clinical course of cancer (41). Somaiah et al. found that the percentage of Ki67 positive cells in normal skin that were in $S-G_{2}$ phase of the cell cycle (cyclin A-positive) were significantly increased after week 1 of radiotherapy, and this increase was maintained at the end of 5 weeks, suggesting that both skin epithelial cells and cancer cells, especially those with a highproliferative index, display an increased homologous recombination frequency (42).

The increased expression of iNOS showed no correlation with the incidence of radiation dermatitis. Nitric oxide (NO) acts as a regulatory agent in the vascular, nervous, and immune system, and contributes to the adhesion and activation of platelets and angiogenesis, especially in irradiated tissues $(43,44)$. Previous studies have also reported that iNOS expression may predict acute skin toxicity in breast cancer patients undergoing radiotherapy $(45,46)$.

Finally, lysosomal aGluc is known to be involved in cancer processes $(47,48)$, while breast cancer risk factors that could initiate the activity of lysosomal enzymes include ionizing radiation and oxidative stress (49). In addition, to the best of our knowledge, no literature data report the direct association of aGluc with radiation dermatitis. Thus, aGluc tissue levels were determined in the present study and no correlation between aGluc expression and the incidence of radial dermatitis was shown.

Even though the molecular targets in question were selected on the basis of extensive literature and research data on breast cancer, radiation therapy, and radiation dermatitis, correlations in all cases presented did not reach statistical significance. This might be due to sample size limitations, since only 122 patients met the inclusion criteria that could produce a highly homogeneous sample. Furthermore, radiation dermatitis is a complex trait that consists of genetic and environmental components and whose mechanisms slowly unravel through radiogenomics.

Rattay and Talbot reported that after the evolution of DNA sequencing and bioinformatics, radiogenomics has emerged as a new research field aiming to reveal the genetic determinants of adverse reactions to radiotherapy (50). Ultimately, radiogenomics is focused on the prediction of cancer patients that might develop radiosensitivity or radioresistance, aiming to reduce adverse reactions or increase the efficacy of radiotherapy $(9,51-54)$. It is now well-established that clinical radiosensitivity, which varies greatly among cancer patients, can be an critical limiting factor of therapy (54). So far, several molecular mechanisms have been proposed, in which DNA repair mechanisms and damage detoxification processes are considered fundamental (9).

In this study, although histopathological analysis did not show any statistical significant difference, pathway and network analyses revealed interactions of proteins involved in tumor growth (Ki67, ATM) and/or affect the oxidation state of the cell (HIF-1a, iNOS, aGluc), which may contribute to the risk of developing acute radiation dermatitis (Figure 1). Such findings predict that vasodilation and angiogenesis contribute to radiation-induced dermatitis in the studied breast cancer patient cohort. Herein, the expression of selected molecular markers was determined in breast tumor specimens of women who developed any degree of radiation dermatitis (non-tumor tissue) implying a role for both proximal and distant cell-cell communication. This hypothesis needs to be explored further.

\section{Conclusion}

Radiation dermatitis (RTOG grading) and the increased expression of Ki67, ATM, iNOS, HIF-1 $\alpha$, and aGluc observed in women undergoing postoperative radiotherapy became evident, even though our study failed to reach statistical significance when skin type and/or body weight were considered, possibly due to sample size limitations and stringent inclusion criteria. Network interactions of proteins involved in tumor growth (Ki67, ATM) and/or affecting the oxidation state of the cell (HIF-1 $\alpha$, iNOS, aGluc) were revealed, that may contribute to the risk of developing acute radiation dermatitis. Further prospective and functional studies should be performed to thoroughly understand the pathways involved in the mechanism of actinic dermatitis development and the identification of high-risk patients as well as the correlation of specific markers with local recurrence and overall survival. Our strategy serves as a paradigm for coupling histopathological data to molecular findings and network analyses for risk assessment in the clinic.

\section{Conflicts of Interest}

There are no conflicts of interest to disclose

\section{References}

1 Kardamakis D, Gustavson-Kadaka E, Spiliopoulou E and Nilsson S: The history of Radiumhemmet in Stockholm in the period 1895-1950. The transformation of an outpatient clinic to an academic department. Vesalius 16(2): 95-99, 2010. 
2 Shah C, Tendulkar R, Smile T, Nanavati A, Manyam B, Balagamwala E, Pham Y, Takiar R, Wobb J and Khan A: Adjuvant Radiotherapy in Early-Stage Breast Cancer: EvidenceBased Options. Ann Surg Oncol 23(12): 3880-3890, 2016.

3 Cox JD, Stetz J and Pajak TF: Toxicity criteria of the radiation therapy oncology group (RTOG) and the European organization for research and treatment of cancer (EORTC). Int J Radiat Oncol Biol Phys 31(5): 1341-1346, 1995.

4 Hickey BE, James ML, Lehman M, Hider PN, Jeffery M, Francis DP and See AM: Fraction size in radiation therapy for breast conservation in early breast cancer. Cochrane Database Syet Rev 7: CD003860, 2016.

5 Kraus-Tiefenbacher U, Sfintizky A, Welzel G, Simeonova A, Sperk E, Siebenlist K, Mai S and Wenz F: Factors of influence on acute skin toxicity of breast cancer patients treated with standard three-dimensional conformal radiotherapy (3D-CRT) after breast conserving surgery (BCS). Radiat Oncol 7(1): 217, 2012.

6 Bray FN, Simmons BJ, Wolfson AH and Nouri K: Acute and chronic cutaneous reactions to ionizing radiation therapy. Dermatol Ther 6(2): 185-206, 2016.

7 Baumann M, Bodis S, Dikomey E, van der Kogel A, Overgaard J, Rodemann HP and Wouters B: Molecular radiation biology/oncology at its best: cutting edge research presented at the 13th International Wolfsberg Meeting on Molecular Radiation Biology/Oncology. Radiother Oncol 108(3): 357, 2013.

8 Bartsch H, Dally H, Popanda O, Risch A and Schmezer P: Genetic risk profiles for cancer susceptibility and therapy response, in Cancer Prevention. Springer. Recent Results Cancer Res 174: 19-36, 2007.

9 Mangoni M, Bisanzi S, Carozzi F, Sani C, Biti G, Livi L, Barletta E, Costantini AS and Gorini G: Association between genetic polymorphisms in the XRCC1, XRCC3, XPD, GSTM1, GSTT1, MSH2, MLH1, MSH3, and MGMT genes and radiosensitivity in breast cancer patients. Int $\mathrm{J}$ Radiat Oncol Biol Phys 81(1): 52-58, 2011.

10 Hymes SR, Strom EA and Fife C: Radiation dermatitis: clinical presentation, pathophysiology, and treatment 2006. J Am Acad Dermatol 54(1): 28-46, 2006.

11 Hird AE, Wilson J, Symons S, Sinclair E, Davis M and Chow E: Radiation recall dermatitis: case report and review of the literature. Curr Oncol 15(1): 53, 2008.

12 Kole AJ, Kole L and Moran MS: Acute radiation dermatitis in breast cancer patients: challenges and solutions. Breast Cancer (Dov NEd Press) 9: 313, 2017.

13 Siiskonen H, Smorodchenko A, Krause K and Maurer M: Ultraviolet radiation and skin mast cells: Effects, mechanisms, and relevance for skin diseases. Exp Dermatol 27(1): 3-8, 2018

14 Liao W, Hei TK and Cheng SK: Radiation-Induced Dermatitis is Mediated by IL17-Expressing $\gamma \delta \mathrm{T}$ Cells. Radiation Res 187(4): 464-474, 2017.

15 Lee J, Park W, Choi DH, Huh SJ, Kim I-R, Kang D and Cho J: Patient-reported symptoms of radiation dermatitis during breast cancer radiotherapy: a pilot study. Qual Life Res: 1-7, 2017.

16 Xie G, Ao X, Lin T, Zhou G, Wang M, Wang H, Chen Y, Li X, Xu B, He W, Han H, Ramot Y, Paus R and Yue Z: E-cadherinmediated Cell Contact Controls the Epidermal Damage Response in Radiation Dermatitis. J Invest Dermatol 137(8): 1731-1739, 2017
17 Camidge $\mathrm{R}$ and Price A: Characterizing the phenomenon of radiation recall dermatitis. Radiother Oncol 59(3): 237-245, 2001.

18 Levy A, Chargari C, Marabelle A, Perfettini J-L, Magné N and Deutsch E: Can immunostimulatory agents enhance the abscopal effect of radiotherapy? Eur J Cancer 62: 36-45, 2016.

19 Green DR, Ferguson T, Zitvogel L and Kroemer G: Immunogenic and tolerogenic cell death. Nat Rev Immunol 9(5): 353-363, 2009.

20 Casares N, Pequignot MO, Tesniere A, Ghiringhelli F, Roux S, Chaput N, Schmitt E, Hamai A, Hervas-Stubbs S and Obeid M: Caspase-dependent immunogenicity of doxorubicin-induced tumor cell death. J Exp Med 202(12): 1691-1701, 2005.

21 Villarreal L, Méndez O, Salvans C, Gregori J, Baselga J and Villanueva J: Unconventional secretion is a major contributor of cancer cell line secretomes. Mol Cell Proteomics 12(5): 10461060, 2013.

22 Fitzpatrick TB: The validity and practicality of sun-reactive skin types I through VI. Arch Dermatol 124(6): 869-871, 1988.

23 Kourea HP, Nikolaou M, Tzelepi V, Adonakis G, Kardamakis D, Tsapanos V, Scopa CD, Kalofonos C and Decavalas G: Expression of phosphorylated Akt, mTOR and MAPK in type I endometrial carcinoma: Clinical significance. Anticancer Res 35(4): 2321-2331, 2015.

24 Szklarczyk D, Franceschini A, Wyder S, Forslund K, Heller D, Huerta-Cepas J, Simonovic M, Roth A, Santos A and Tsafou KP: STRING v10: protein-protein interaction networks, integrated over the tree of life. Nucleic Acids Res 43(Database issue): D447-452, 2015.

25 Szklarczyk D, Morris JH, Cook H, Kuhn M, Wyder S, Simonovic M, Santos A, Doncheva NT, Roth A and Bork P: The STRING database in 2017: quality-controlled protein-protein association networks, made broadly accessible. Nucleic Acids Res 45(Database issue): D362-D368, 2017.

26 Breuer K, Foroushani AK, Laird MR, Chen C, Sribnaia A, Lo R, Winsor GL, Hancock RE, Brinkman FS and Lynn DJ: InnateDB: systems biology of innate immunity and beyond-recent updates and continuing curation. Nucleic Acids Res: gks1147, 2012.

27 Shannon P, Markiel A, Ozier O, Baliga NS, Wang JT, Ramage D, Amin N, Schwikowski B and Ideker T: Cytoscape: a software environment for integrated models of biomolecular interaction networks. Genome Res 13(11): 2498-2504, 2003.

28 De Langhe S, Mulliez T, Veldeman L, Remouchamps V, van Greveling A, Gilsoul M, De Schepper E, De Ruyck K, De Neve $\mathrm{W}$ and Thierens $\mathrm{H}$ : Factors modifying the risk for developing acute skin toxicity after whole-breast intensity modulated radiotherapy. BMC Cancer 14(1): 711, 2014.

29 Ott OJ, Strnad V, Hildebrandt G, Kauer-Dorner D, Knauerhase H, Major T, Łyczek J, Guinot JL, Dunst J and Miguelez CG: GEC-ESTRO multicenter phase 3-trial: Accelerated partial breast irradiation with interstitial multicatheter brachytherapy versus external beam whole breast irradiation: Early toxicity and patient compliance. Radiother Oncol 120(1): 119-123, 2016.

30 Ulff E, Maroti M, Serup J and Falkmer U: A potent steroid cream is superior to emollients in reducing acute radiation dermatitis in breast cancer patients treated with adjuvant radiotherapy. A randomised study of betamethasone versus two moisturizing creams. Radiother Oncol 108(2): 287-292, 2013.

31 Abbas H, Elyamany A, Salem M, Salem A, Binziad S and Gamal B: The optimal sequence of radiotherapy and 
chemotherapy in adjuvant treatment of breast cancer. Int Arch Med 4(1): 35, 2011.

32 Iannuzzi CM, Atencio DP, Green S, Stock RG and Rosenstein BS: ATM mutations in female breast cancer patients predict for an increase in radiation-induced late effects. Int J Radiat Oncol Biol Phys 52(3): 606-613, 2002.

33 Bremer M, Klöpper K, Yamini P, Bendix-Waltes R, Dörk T and Karstens JH: Clinical radiosensitivity in breast cancer patients carrying pathogenic ATM gene mutations: no observation of increased radiation-induced acute or late effects. Radiother Oncol 69(2): 155-160, 2003.

34 Ross JG, Hussey DH, Mayr NA and Davis CS: Acute and late reactions to radiation therapy in patients with collagen vascular diseases. Cancer 71(11): 3744-3752, 1993.

35 Rouault-Pierre K, Hamilton A and Bonnet D: Effect of hypoxiainducible factors in normal and leukemic stem cell regulation and their potential therapeutic impact. Expert Opin Biol Ther 16(4): 463-476, 2016.

36 Moeller B and Dewhirst M: HIF-1 and tumour radiosensitivity. Br J Cancer 95(1): 1-5, 2006.

37 van der Groep P, van Diest PJ, Smolders YH, Ausems MG, van der Luijt RB, Menko FH, Bart J, de Vries EG and van der Wall E: HIF- $1 \alpha$ overexpression in ductal carcinoma in situ of the breast in BRCA1 and BRCA2 mutation carriers. PLoS One $8(2)$ : e56055, 2013.

38 Zagouri F, Sergentanis TN, Gazouli M, Tsigginou A, Dimitrakakis C, Papaspyrou I, Eleutherakis-Papaiakovou E, Chrysikos D, Theodoropoulos G and Zografos GC: HSP90, HSPA8, HIF-1 alpha and HSP70-2 polymorphisms in breast cancer: a case-control study. Mol Biol Rep 39(12): 1087310879, 2012.

39 Zhang Y, Liu Z, Wang M, Tian H, Su K, Cui J, Dong L and Han F: Single nucleotide polymorphism rs1801516 in ataxia telangiectasia-mutated gene predicts late fibrosis in cancer patients after radiotherapy: a PRISMA-compliant systematic review and meta-analysis. Medicine 95(14): e3267, 2016.

40 Oppitz U, Bernthaler U, Schindler D, Sobeck A, Hoehn H, Platzer M, Rosenthal A and Flentje M: Sequence analysis of the ATM gene in 20 patients with RTOG grade 3 or 4 acute and/or late tissue radiation side effects. Int J Radiat Oncol Biol Phys 44(5): 981-988, 1999.

41 Ohara M, Matsuura K, Akimoto E, Noma M, Nishizaka T, Kagawa N and Itamoto T: Prognostic value of Ki67 and p53 in patients with estrogen receptor-positive and human epidermal growth factor receptor 2-negative breast cancer: Validation of the cut-off value of the Ki67 labeling index as a predictive factor. Mol Clin Oncol 4(4): 648-654, 2016.

42 Somaiah N, Yarnold J, Daley F, Pearson A, Gothard L, Rothkamm $\mathrm{K}$ and Helleday $\mathrm{T}$ : The relationship between homologous recombination repair and the sensitivity of human epidermis to the size of daily doses over a 5-week course of breast radiotherapy. Clin Cancer Res 18(19): 5479-5488, 2012.
43 Ying L and Hofseth LJ: An emerging role for endothelial nitric oxide synthase in chronic inflammation and cancer. Cancer Res 67(4): 1407-1410, 2007.

44 Hatjikondi O, Ravazoula P, Kardamakis D, Dimopoulos J and Papaioannou S: In vivo experimental evidence that the nitric oxide pathway is involved in the X-ray-induced antiangiogenicity. Br J Cancer 74(12): 1916, 1996.

45 Sonveaux P, Brouet A, Havaux X, Grégoire V, Dessy C, Balligand J-L and Feron O: Irradiation-induced angiogenesis through the up-regulation of the nitric oxide pathway. Cancer Res 63(5): 1012-1019, 2003.

46 Terrazzino S, La Mattina P, Masini L, Caltavuturo T, Gambaro G, Canonico PL, Genazzani AA and Krengli M: Common variants of eNOS and XRCC1 genes may predict acute skin toxicity in breast cancer patients receiving radiotherapy after breast conserving surgery. Radiother Oncol 103(2): 199-205, 2012.

47 Okuyama M, Saburi W, Mori H and Kimura A: $\alpha$-Glucosidases and $\alpha-1,4$-glucan lyases: structures, functions, and physiological actions. Cell Mol Life Sci 73(14): 2727-2751, 2016.

48 Astudillo L, Therville N, Colacios C, Ségui B, Andrieu-Abadie $\mathrm{N}$ and Levade $\mathrm{T}$ : Glucosylceramidases and malignancies in mammals. Biochimie 125: 267-280, 2016.

49 Tappel A: Lysosomal enzymes and initiation of breast cancer. Med Hypotheses 64(2): 288-289, 2005.

50 Rattay $\mathrm{T}$ and Talbot C: Finding the genetic determinants of adverse reactions to radiotherapy. Clinical Oncology 26(5): 301308, 2014.

51 Numata I, Okuyama R, Memezawa A, Ito Y, Takeda K, Furuyama K, Shibahara S and Aiba S: Functional expression of heme oxygenase- 1 in human differentiated epidermis and its regulation by cytokines. J Invest Dermatol 129(11): 2594-2603, 2009.

52 Beaudry VG, Pathak N, Koster MI and Attardi LD: Differential PERP regulation by TP63 mutants provides insight into AEC pathogenesis. Am J Med Genet A 149(9): 1952-1957, 2009.

53 Werbrouck J, De Ruyck K, Duprez F, Veldeman L, Claes K, Van Eijkeren M, Boterberg T, Willems P, Vral A and De Neve W: Acute normal tissue reactions in head-and-neck cancer patients treated with IMRT: influence of dose and association with genetic polymorphisms in DNA DSB repair genes. Int J Radiat Oncol Biol Phys 73(4): 1187-1195, 2009.

54 Andreassen CN, Alsner J and Overgaard J: Does variability in normal tissue reactions after radiotherapy have a genetic basiswhere and how to look for it? Radiother Oncol 64(2): 131-140, 2002 . 